\title{
CORRIGENDUM
}

\section{Queensland's broad-scale land-clearing policy debate, 1998-2006: An analysis of evidence-based arguments in news media content-CORRIGENDUM}

\author{
Nathan Laurent and Lee Duffield
}

DOI: https://doi.org/10.1017/qre.2018.8, Published online by Cambridge University Press, $4^{\text {th }}$ June 2018.

In the above mentioned article by Laurent and Duffield, the same figure was included twice as figure 4 and 5 instead of different figures. The correct version of figure 5 and caption is below.

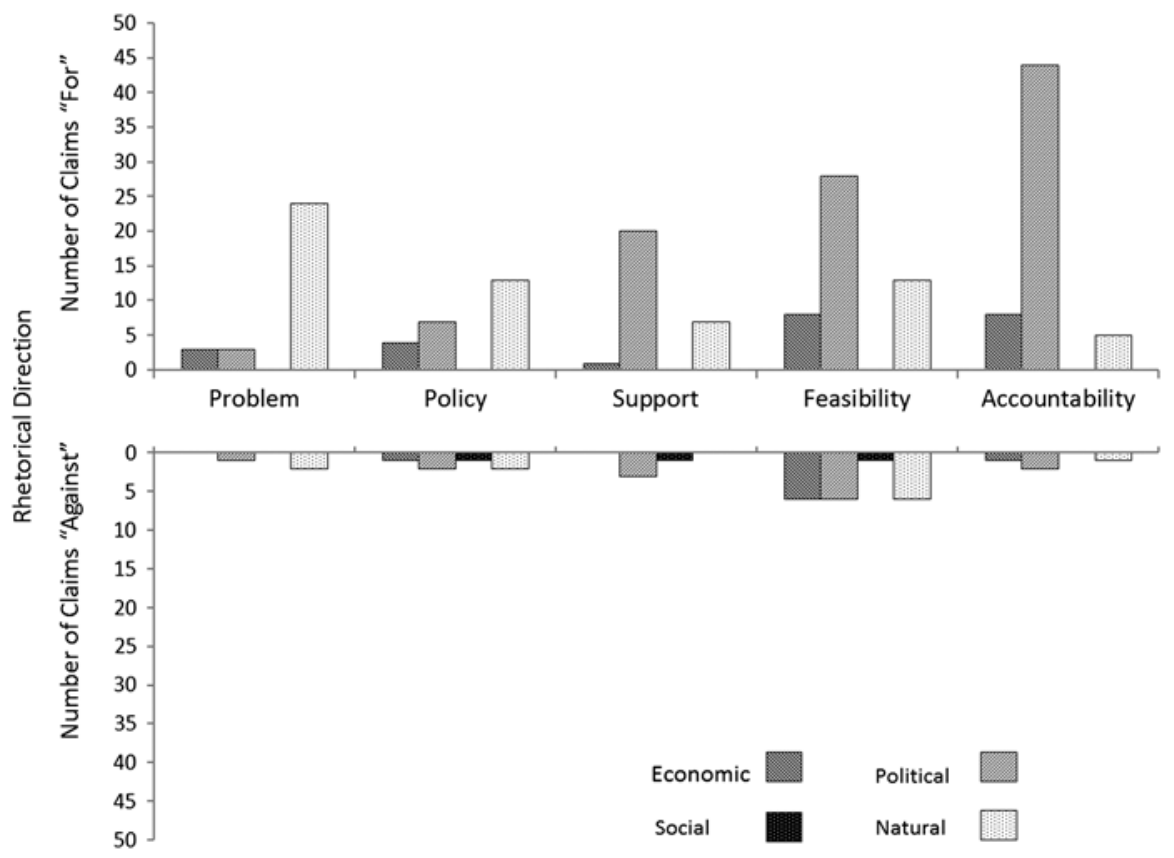

Figure 5

Coding for claims 'for' and 'against' by policy issue criteria categories (PIC1-PIC5), CM, 1998-2006. 


\section{Reference}

Laurent, N., and Duffield, L. (2018). Queensland's broad-scale land-clearing policy debate, 1998-2006: An analysis of evidence-based arguments in news media content. Queensland Review, 25(1), 70-88. doi:10.1017/qre.2018.8 